\title{
On the Ladle Shroud Design and Mis-alignment Effects on the Fluid Flow in a Metallurgical Tundish- A CFD Model Study
}

\author{
Lei Chen ${ }^{1}$, Jun-song Chen², Yu-qian $\mathrm{Li}^{2}$, She-bin Wang ${ }^{2}$, and Chao Chen ${ }^{2 *}$ \\ ${ }^{1}$ Leiyan Technology Corporation, 030024 Binxi industrial park Zone A no.5, Taiyuan City, Shanxi Province, P.R. China. \\ ${ }^{2}$ College of Materials Science and Engineering, Taiyuan University of Technology, 030024 Yingze West Street No. 79, Taiyuan City, \\ Shanxi Province, P.R. China.
}

\begin{abstract}
Two aspects of ladle shroud design in tundish are studied. The two strand tundish is a long and bare tundish i.e. without flow control devices but stopper rods to control flowrate. The 3D CAD geometry, turbulence models, discretisation of governing equations, numerical solution and post processing are performed in a commercial software Siemens STAR CCM+. Compared to the typical pipe ladle shroud, the velocity of impinging stream from the ladle shroud is lower for the trumpet ladle shroud. As a result, the flow stream in the whole tundish shows a contradictory tendency, i.e. the upward stream is more obvious than the downward stream for trumpet shroud and vice visa for pipe shrouds. In industrial production, the ladle shroud often canted to the front wall due to machinery reasons. Therefore, two cases that the misalignment degree of the ladle shroud are 5 and 10 degrees are studied. The results show that the impinging stream flow towards the front side of walls and the flow towards the outlets near the bottom wall and front wall. The horse like vortex that is typically observed in bare tundishes is destroyed. The non-symmetric flow pattern is formed for the severely biased cases which should be paid more attentions from industrial practice.
\end{abstract}

\section{Introduction}

Steel is the most widely used engineering material. The crude steel production reached 1.87 billion tonnes in the year of 2019 . More than $95 \%$ of the steel are produced by continuous casting processes. Traditionally, the tundish is an intermediate vessel which is placed between a discontinuous teeming ladle (refining process) and a continuous casting mould. In the early 1980's, the concept of tundish metallurgy was put forward by Heaslip and McLean ${ }^{[1]}$. The tundish plays a role increasing in composition, temperature and cleanness control rather than merely the casting speed control. The modelling and industrial progress were well-documented in reviews papers ${ }^{[2-6]}$. The optimization of fluid flow in tundish via flow control devices (FCD), e.g. weir, dam, baffle, turbo-stopper etc. have been well studied ${ }^{[7-10]}$. As a compromise between the extra cost of refractories in tundish and acceptable steel quality, bare tundish, i.e. without FCD has been widely used in industry. A typical tundish is shown in Fig.1.

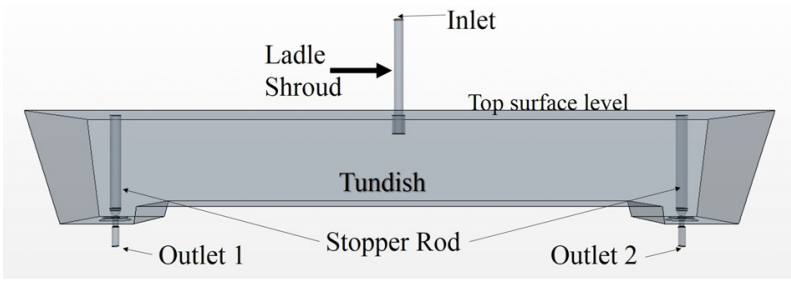

Fig. 1. Construction of tundish and ladle shroud
Ladle shroud is a refractory tube used to transfer molten steel from the ladle to tundish. In recent years, new strategies are used to develop the ladle shrouds, e.g. dissipative shroud [11-12] and trumpet shroud ${ }^{[13-15]}$.In practice, mis-alignment of a ladle shroud has been frequently observed (as typically shown in Fig.2) due to the difficulties to position the heavy equipment and the limitation of holding technology.

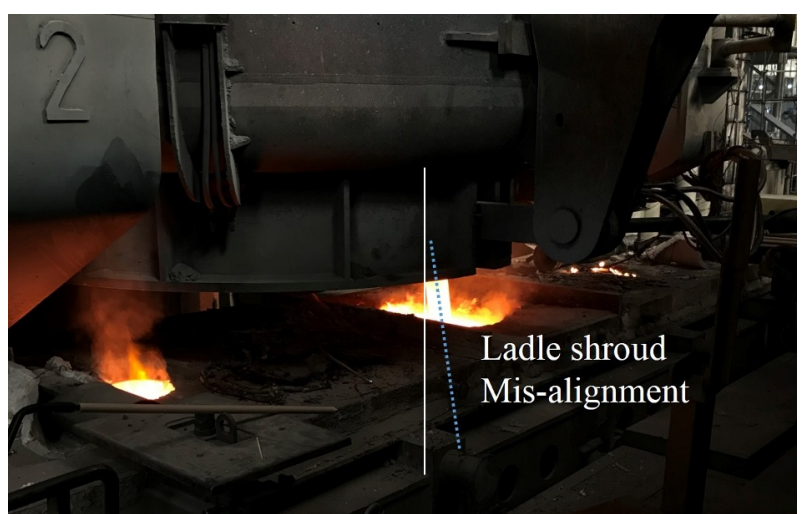

Fig. 2. Mis-alignment of ladle shroud in a steelmaking plant

The effect of mis-alignment of ladle shroud on the fluid flow in a delta-shape four strand tundish was studied by Chattopadhyay et al. ${ }^{[16-18]}$. In the study, the four strand (outlets) tundish is non-symmetric, i.e. the inlet and four outlets are located at both side of width direction of tundish. The ladle shroud canted towards the back wall, front wall, and outlet direction are studied.

\footnotetext{
* Corresponding author: chenchao@tyut.edu.cn
} 
The ladle shroud mis-alignment in a two strand 'long' tundish or single strand tundish have not been studied.

In this study, the two strand tundish in Baogang Group as shown in Fig.1 are studied. The bare tundish shows a high length to height ratio. The horse like vortex in tundish has been observed. Therefore, three types of ladle shroud e.g. trumpet shroud and mis-alignment of ladle shroud are the main focus in this study to improve the understanding of ladle shroud in practice. Computational fluid dynamics (CFD) are used to the study the fluid flow under different operation conditions.

\section{CFD Model and Studied Cases}

\subsection{Geometry of tundish and studied cases}

The configuration of tundish could be found in Fig.1. Specifically, two outlets as well as stopper rod (flowrate control) are located at two sides of the tundish. The ladle shroud could be the only one FCD to control the flow in tundish. Three type of shrouds are designed and are shown in Fig.3. The shroud 1 and shroud 2 are straight pipes with varying diameters. The shroud 3 is a trumpet shape shroud with a large diameter in the entrance part. (a) Shroud 1

(b) Shroud 2

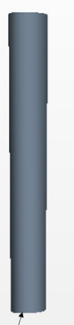

Inner diameter $110 \mathrm{~mm}$

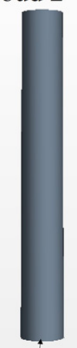

Inner diameter $120 \mathrm{~mm}$ Inner diameter $226 \mathrm{~mm}$

Fig. 3. Three types of ladle shrouds in the study

\subsection{CFD Model description}

The 3D geometries of industrial tundish are established and converted into a commercial software Siemens STAR CCM+ ${ }^{[19]}$. To simplify, the top surface is flat and kept at a fixed level. The chemical reactions as well as heat transfer are neglected. The liquid flow is assumed to be isothermal and in steady state. Based on mass balance principle, the inlet velocity and outlet mass flowrate are derived from the industrial production conditions, i.e. casting speed $1 \mathrm{~m} / \mathrm{min}$ and cross section of slab: 2000 $\mathrm{mm}$ width times $230 \mathrm{~mm}$ thickness. The density and viscosity of liquid steel are $7000 \mathrm{~kg} / \mathrm{m}^{3}$ and 0.005975 $\mathrm{Pa} \cdot \mathrm{s}$, respectively. The Realizable Two-Layer $k-\varepsilon$ model, which combines the realizable $k-\varepsilon$ model ${ }^{[20]}$ with the two-layer approach proposed by Rodi ${ }^{[21]}$, is applied to calculate the turbulent flow in tundish. The formula are not reproduced here and can be found in reference ${ }^{[22]}$. The volume mesh is generated in STAR CCM+, utilizing the trimmer and prism layer meshing options. As shown in Fig.4, a fine mesh is generated next to the walls and the cell number in total are close to 0.5 million. The second-order upwind scheme is used to calculate the convective flux in the momentum equations. The discretized equations are solved by using the semiimplicit method for the pressure-linked equations (SIMPLE) algorithm ${ }^{[23]}$. A criterion of less than $10^{-4}$ is used to judge the convergence.
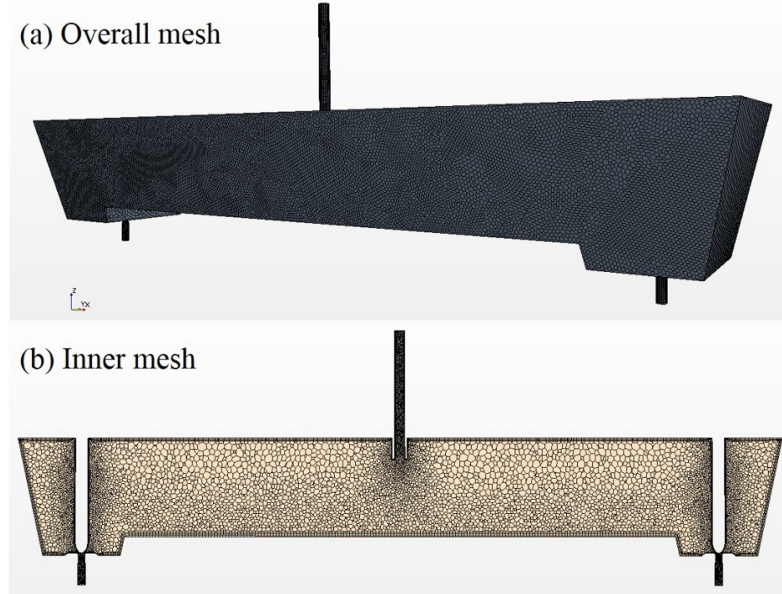

Fig. 4. Mesh of the ladle shroud and tundish system

\section{Results and Discussions}

In this section, the fluid flow for three ladle shroud will be presented first, followed by the results of misalignment of ladle shroud.

\subsection{Fluid flow for three ladle shroud designs}

The velocity vectors of three type of ladle shroud designs at width direction and length direction are shown in Fig.5 and Fig. 6, respectively. The velocity file and the flow pattern are similar for ladle shroud 1 and 2 . The velocity of impinging stream from the ladle shroud 3 (trumpet shroud) is lower than that of ladle shroud 1 and 2. Thereafter, the circulation flow near the front and back walls (side view) is not as strong as that of ladle shroud 1 and 2. As shown in Fig.6, the flow velocity in the whole tundish is also lower for ladle shroud 3.

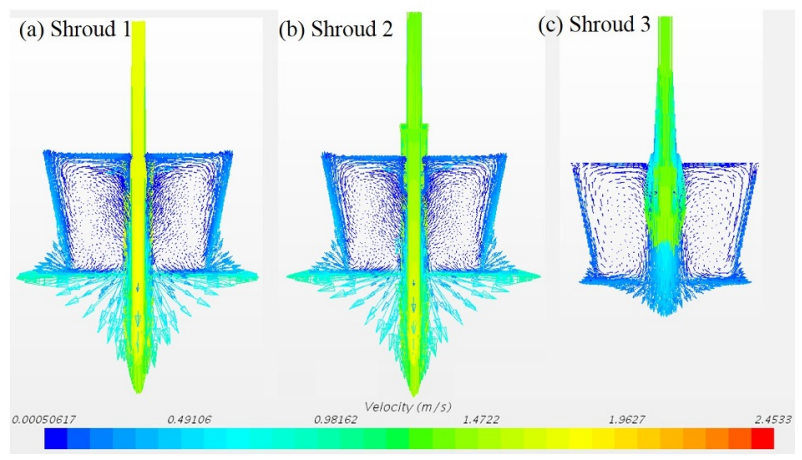

Fig. 5. Velocity vectors of three type of shroud designs (cross section at width direction)

(a) Shroud 1

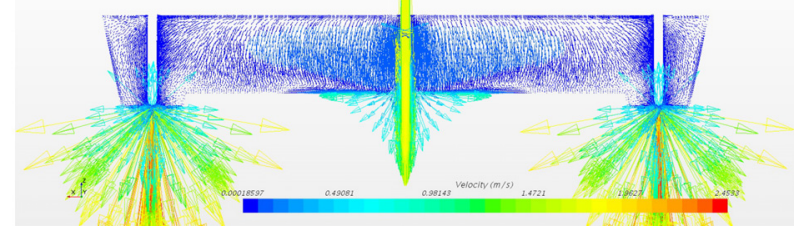




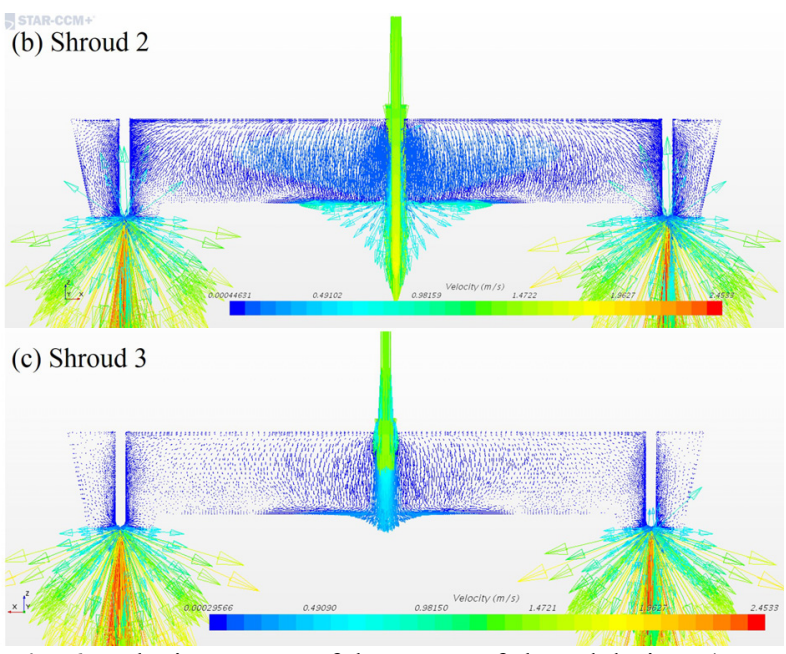

Fig. 6. Velocity vectors of three type of shroud designs (cross section at length direction)

The streamlines of three type of ladle shroud designs of front view and top view are shown in Fig.7 and Fig. 8, respectively. As described before, the streamlines are similar for ladle shroud 1 and 2. The vortex near the impinging part is enhanced for the trumpet shroud as shown in Fig.7 (c). As a result, the upward stream is more obvious than the downward stream. On the contrary, the downstream is stronger than the upward stream for ladle shroud 1 and 2.

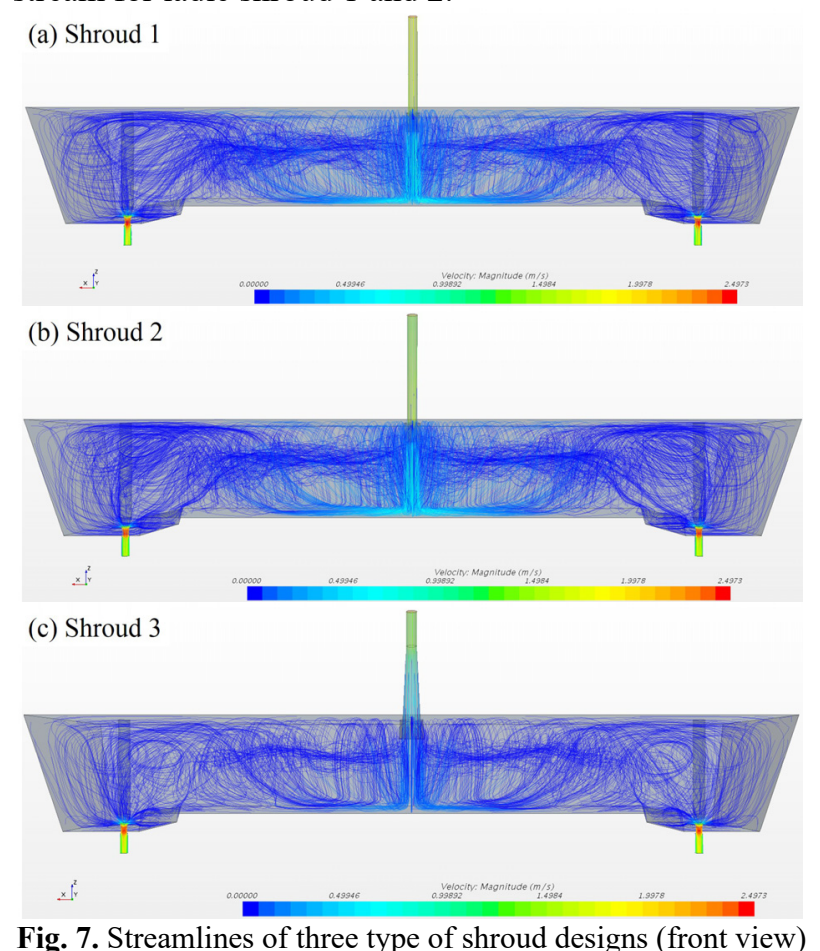

Fig. 7. Streamlines of three type of shroud designs (front view)

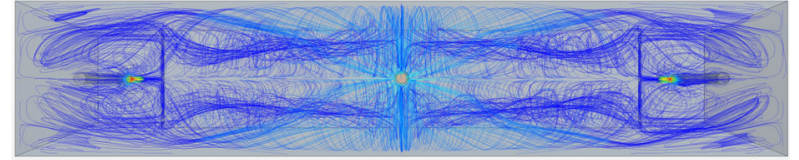

(a) Shroud 1

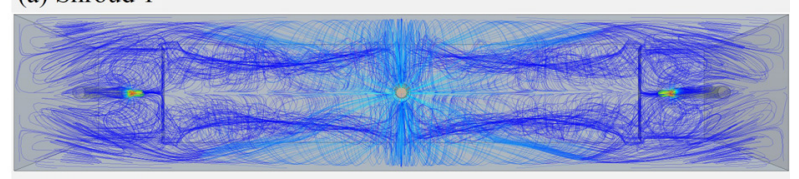

(b) Shroud 2

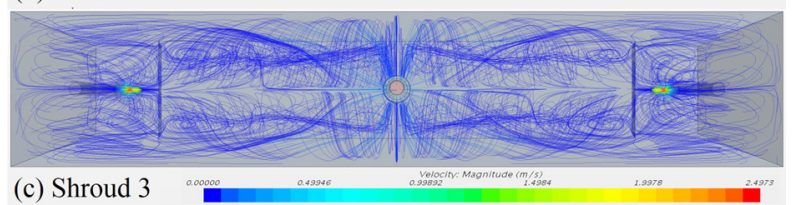

Fig. 8. Streamlines of three type of shroud designs (top view)

\subsection{Effects of mis-alignment of ladle shroud on fluid flow in tundish}

In industrial production, the ladle shroud often canted to the front wall due to machinery reasons. Therefore, two cases that the mis-alignment degree of the ladle shroud are 5 and 10 degrees are studied. The velocity vectors and streamlines are shown in Fig.9 to Fig. 12. From Fig.9, the impinging stream flow towards the front side of walls for both the 5 and 10 degree biased cases. As a result, the flow velocity near the bottom wall is increased for both cases. As shown in Fig.10, the upward flow is enhanced for the biased cases.

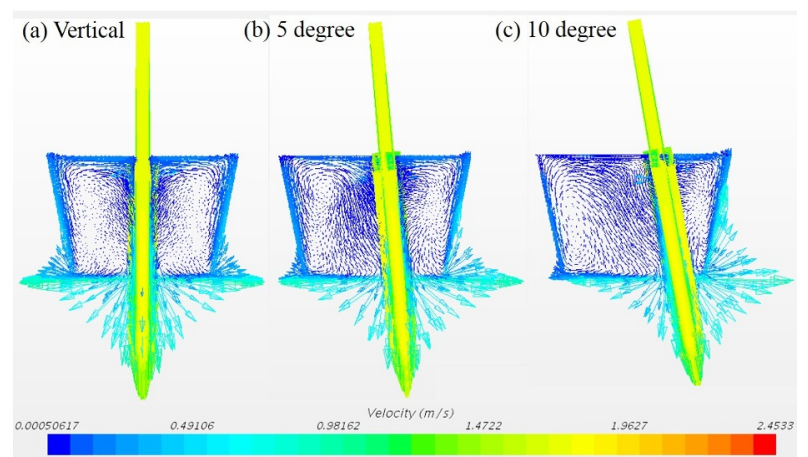

Fig. 9. Effect of mis-alignment degree on the flow velocity vectors (cross section at width direction)

(a) 5 degree

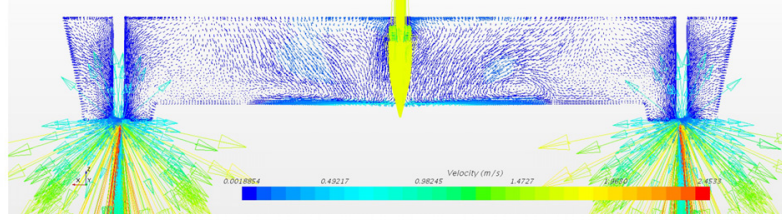

(b) 10 degree

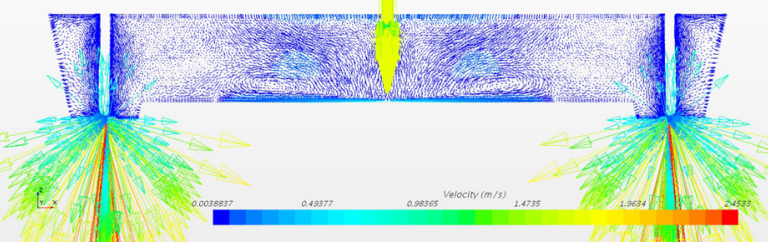

Fig. 10. Effect of mis-alignment degree on the flow velocity vectors (cross section at length direction) 

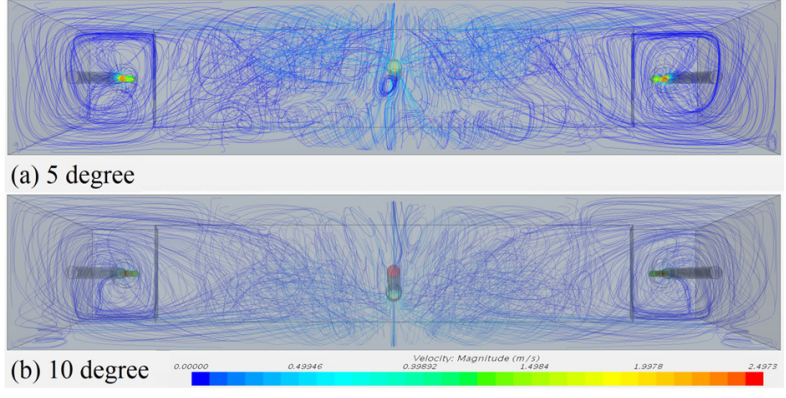

Fig. 11. Effect of mis-alignment degree on the streamlines (top view)

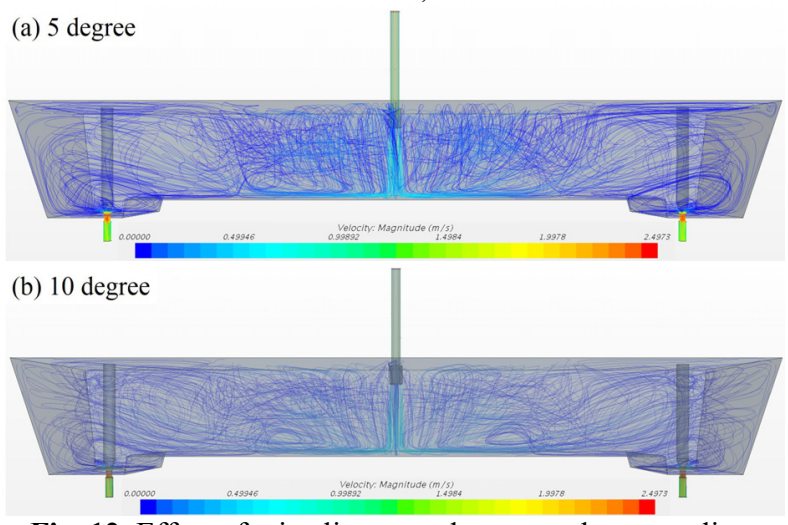

Fig. 12. Effect of mis-alignment degree on the streamlines (front view)

Compared with the Fig.7(a) and Fig. 8(a), the flow pattern is quite different. The horse like vortex is destroyed and non-symmetric flow is formed. For the 10 degree biased case, the flow stream is more close to the front wall and the horse like vortex is destroyed even worse than that of the 5 degree biased case. Besides, the velocity magnitude is smaller for the 10 degree biased case.

\section{Conclusion}

The effect of three type of ladle shroud on fluid flow are studied. Due to the dissipation of flow in the trumpet ladle shroud, the velocity of impinging stream from the ladle shroud is lower. As a result, the flow streamline in the whole tundish shows a different tendency, i.e. the upward stream is more obvious than the downward stream for trumpet shroud and vice visa for pipe shrouds. Second, the mis-alignment of ladle shroud are studied. The impinging stream flow towards the front side of walls and the flow towards the outlets near the bottom wall and front wall. A non-symmetric flow pattern is formed in the mis-alignment cases. The horse like vortex is destroyed even worse for the severely biased cases. In practice, the mis-alignment of ladle shroud may cause severe effects on flow and steel quality.

\section{Acknowledgments}

The financial support of Baogang Group is acknowledged.

\section{References}

1. L.J. Heaslip, A. McLean, Proceedings of the 39th Electric Furnace Conference, 333 (1981)

2. D. Mazumdar, R.I.L. Guthrie, ISIJ Int., 39, 524 (1999)

3. K. Chattopadhyay, M. Isac, R.I.L. Guthrie, ISIJ Int., 50, 331 (2010)

4. Y. Sahai, Metall. Mater. Trans. B, 47B, 2095 (2016)

5. D. Mazumdar, Steel Res. Int., 90, 1800279 (2019)

6. J. Zhang, Q. Liu, S. Yang, Z. Chen, J. Li, Z. Jiang, ISIJ Int., 59, 1167 (2019)

7. C. Chen, G. Cheng, H. Sun, Z. Hou, X. Wang, J. Zhang, Steel Res. Int., 83, 1141 (2012)

8. C. Chen, L.T.I. Jonsson, A. Tilliander, G. Cheng, P.G. Jönsson, Metall. Mater. Trans. B, 46B, 169 (2015)

9. C. Chen, L.T.I. Jonsson, A. Tilliander, G. Cheng, P.G. Jönsson, Chem. Eng. Sci., 137, 914 (2015)

10. C. Chen, P. Ni, L.T.I. Jonsson, A. Tilliander, G. Cheng, P.G. Jönsson, Metall. Mater. Trans. B, 47B, 1916 (2016)

11. S.G. Hernández, J. de J. Barreto, R.D. Morales, A.C. Huerta, E. Gutiérrez, $20^{\text {th }}$ Conferencia del Acero IAS \& $20^{\text {th }}$ IAS Steel Conference, 391 (2014)

12. J. Zhang, S. Yang, J. Li, W. Yang, Y. Wang, X. Guo, ISIJ Int., 55, 1684 (2015)

13. J. Zhang, J. Li, Y. Yan, Z. Chen, S. Yang, J. Zhao, Z. Jiang, Metall. Mater. Trans. B, 47B, 495 (2016)

14. J. Zhang, S. Yang, Y. Chen, Z. Chen, J. Zhao, J. Li, Z. Jiang, JOM, 70, 2886 (2018)

15. H. Zhang, Q. Fang, S. Deng, C. Liu, H. Ni, Steel Res. Int., 90, 1800497 (2019)

16. K. Chattopadhyay, F.G. Liu, M. Isac, R.I.L. Guthrie, Ironmak. Steelmak., 38, 112 (2011)

17. K. Chattopadhyay, M. Isac, R.I.L. Guthrie, ISIJ Int., 51, 759 (2011)

18. K. Chattopadhyay, J. Young, AISTech 2013 Proceedings, 2123 (2013)

19. https://www.plm.automation.siemens.com/global/en /products/simcenter/STAR-CCM.html, Accessed in July 2020.

20. T.H. Shin, W.W. Liou, A. Shabbir, Z.G. Yang, J. Zhu, Comp. Fluids, 24, 227 (1995)

21. W. Rodi, 29th Aerospace Sciences Meeting, 1(1991)

22. Y. Zhang, C. Chen, W. Lin, Y. Yu, D. E, S. Wang, Steel Res. Int., 91, 2000022 (2020)

23. S.V. Patankar, D.B. Spalding, Int. J. Heat Mass Trasnf., 15, 1787 (1972) 